enzyme system in the liver and the variable effects of the major groups of inducing agents is followed by an account of the relationship between bone disease of various types and the probable alteration of Vitamin D metabolism produced by anti-epileptic drugs.

The two major 'liver' enzymes of diagnostic importance in clinical practice are separately dealt with. The value in particular of $5^{\prime}$ nucleotidase and alkaline phosphatase in the diagnosis of liver disease of infancy is stressed and in the chapter on alkaline phosphatase. Regan isoenzyme and its variants are included.

A chapter describing the major routes of alcohol metabolism in the hepatocyte, their relative importance, and the effects of alcohol on the metabolism of other compounds is followed by an interesting and extensive review of the many abnormalities of enzyme secretion and control found in autonomous hepatic tumours. The subject is a complex and confusing one and the links between the abnormalities noted and the clinical problems of hepatoma are at the moment restricted.

A chapter on bilirubin conjugation and in particular on the properties of the various UDP glycosyltransferases both in the liver and other organs completes this volume.

The papers are excellent and for those looking for an authoritative paper on each of the topics one could not do better. As the approach is rather biochemical it is difficult to see whether this will be a volume that appeals to the clinician as opposed to the research worker. To neither will the price appeal-even by modern standards this is expensive, $£ 34$ for 292 pages.

A. E. READ

Radiology of the Small Intestine By Richard H. Marshak and Arthur E. Lindner (Pp. 620; illustrated; £24.75). Saunders: Philadelphia.

For the second edition of this book, first published five years ago, three new chapters have been added by invited authors, on carcinoma metastatic to the small bowel, angiography, and immunoglobulin deficiency diseases.

For various reasons, small bowel radiology was for many years rather disappointing; a glance at the text and illustrations of this book suffices to show how techniques and knowledge have advanced to the standards of the present day.

The opening chapter is a short survey of examination techniques; here one is surprised at the author's submission that at least one small bowel film should be obtained as part of the routine investigation of the upper gastrointestinal tract. Similarly, there is no mention of metoclopramide which is quite frequently used in the United Kingdom. The remaining chapters cover diseases of the small bowel in systematic fashion. Perusal of the text shows that likely questions are readily answered and criticisms are few. It is, however, surprising that there is only one paragraph on TB, though this reflects its rarity in the United States at the present time. Also, one might have expected some mention of yersinia infection in a current textbook. The authors have sensibly included a chapter on Crohn's colitis and ileocolitis, although the illustrations in this section are, sadly, almost all of single contrast studies.

The text is informative, and easy to read, and this volume can be unhesitatingly recommended to all in the field of gastroenterology. The foreword to the first edition proclaimed that the book would become a radiographic classic; I am sure that it has.

B. M. THOMAS

Surgery of Peptic Ulcer By René Menguy. (Pp. 297; illustrated; £11.00). Saunders: London. 1976. A book of this type, which relies largely on the personal views and experience of René Menguy, demands attention. However, the personal reflections are sometimes hard to find in a text which follows the traditional pattern of presenting this subject. There is little new in the pathophysiology that has not been elaborated in other books. Radiological diagnosis is considered at length with numerous illustrations, whereas endoscopy receives little attention and gastroscopy, though a subheading in the text, is not even listed in the index.

The book is intended for those who may find 'the state of the art confusing'. This may excuse the numerous diagrams of technical manoeuvres. The discussion on surgical treatment of duodenal ulcers is good and includes the author's valuable personal view of proximal gastric vagotomy. The chapter on the sequelae of surgery is less satisfactory and somewhat abbreviated.

Undoubtedly the best part of the book relates to the observations on acute gastric mucosal lesions and, where his advice might be debated, his experience must be respected.

C. G. CLARK
Liver Cell Cancer Edited by H. M. Cameron, D. A. Linsell, and G. P. Warwick (Pp. xvi + 296; \$41.95). Elsevier Scientific Publishing: Amsterdam and New York. 1977.

This is the second book on liver cancer to be published in the last few months. The editors and contributors are internationally based and include many of the best workers in this area. The clinical features of hepatoma as seen in Africa south of the Sahara are well covered, and there is an excellent account on the geographical pathology of this tumour by Linsell and Higginson. Evidence relating to hepatoma and cirrhosis association is also clearly and topically presented in this chapter, and it is a pity that the same topic is less well considered in some of the subsequent chapters.

For those interested in chemical hepatoxins there is an excellent review of the cell replication underlying liver cancer and the many new studies on the immunological aspects are considered in the final two contributions, although these are somewhat technical in approach.

An expensive but worthwhile volume. ROGER WILLIAMS

\section{The Coeliac Society}

The Coeliac Society have published the 1977-78 List of Gluten-free Manufactured Products. This is the seventh edition of the list and contains a number of deletions and additions, and it replaces all previous editions. It costs $25 \mathrm{p}$, post free. Two of the Society's other publications are the Coeliac Handbook and the Coeliac Condition Booklet. The Handbook contains medical, dietetic, and general chapters as well as recipes and the food list. The price is $£ 1$ post free, although patientmembers do not have to pay the full price. The Coeliac Condition Booklet contains the same main chapters as the Handbook, but not the recipes or food list. Its price is $40 \mathrm{p}$, post free, and it is intended for students and nurses. In June 1977, a gluten-free Recipe Book will be available, price 1 1, post free. Any doctor wishing to have a supply of application forms to make it easier for patients to join the Society should write to the Secretary of the Coeliac Society, Miss Kay Leighton PO Box 181, London, NW2 2QY enclosing a stamped addressed envelope. This form is appropriate not only for patients with newly diagnosed coeliac disease but also for patients with dermatitis herpetiformis. 